Forum Article

\title{
The outcome of surgical management of concha bullosa in patients with headache
}

\begin{abstract}
Background: $\mathrm{CB}$ is a common anatomical variation in nasal cavity, it may be presented with facial pain or headache, proper diagnosis and patient's selection is very important to achieve good results with surgery of CB.

Objective: To study the characteristics of headache due to $\mathrm{CB}$, to study the correlation between xylocaine test response and the outcome of surgery and to study the outcome of surgery(LPT) of CB in patients with headache.

Patients and methods: A prospective study designed in Al-Yarmouk Teaching Hospital, ENT department from May 2015 to March 2016. Twenty patient were included in this study ( 8 male and 12 female), their age ranged from 15 to 38years. These twenty patients were complained from headache of rhinogenic origin. The endoscopic examination showing the presence of mucosal contact areas related to enlarged middle turbinate (concha bullosa on $\mathrm{CT}$ ) in contact with septum medially or in contact with lateral wall at the osteomeatal complex (OMC) region. Xylocaine test done for them. All of them were sent for CT scan of nose and paranasal sinuses. All the patients underwent surgery (lateral partial turbinectomy) under general anesthesia. Patients were followed up for 4months postoperatively.

Results: In our study (60\%) were female and $(40 \%)$ were male, and the third decade was the most common age group. In this study $12(60 \%)$ of our patients had complete relief of headache but 5 patients $(25 \%)$ had partial improvement and only 3 patients had no response $(15 \%)$. So in our study we have $17(85 \%)$ patients responded to surgery but only 3 patients with poor response $(15 \%)$. The post-operative improvement was statistically highly significant as the $\mathrm{p}$ value was 0.003 calculated by binomial method. In our study all those with complete response to xylocaine test had complete relieve of headache, and those with no improvement in their headache had partial response to xylocaine test, indicating that the xylocaine test is good prognostic indicator.
\end{abstract}

Conclusion: In patients with headache due to concha bullosa the outcome of surgery is highly significant, especially in those with good response to xylocaine test.

Keywords: concha bullosa, headache, mucosal contact point, xylocaine test
Volume 7 Issue 5 - 2017

\author{
Adnan Qahtan Khalaf,' Ferial Shakir, ${ }^{2}$ Abdul \\ Hussein kareem Saad, ${ }^{3}$ Mahmood Shaki ${ }^{4}$ \\ 'ENT Specialist laser Specialist in Otolaryngology AI Yarmulke \\ teaching hospital, Iraq \\ ${ }^{2}$ ENT Specialist Al Yarmulke teaching hospital, Iraq \\ ${ }^{3}$ ENT Specialist, Almustansirya University,Al-Yarmouk Teaching \\ Hospital, Iraq \\ ${ }^{4}$ Al-Yarmouk Teaching Hospital/ M.O.H, Iraq
}

Correspondence: Adnan Qahtan Khalaf, ENT Specialist, laser Specialist in Otolaryngology, Al-Yarmulke teaching hospital, Iraq, Tel 964770084 3208,Email andan_khtan@yahoo.com

Received: May 25, 2017 | Published: June 15, 2017
Abbreviations: LCB, lamellar concha bullosa; $\mathrm{BCB}$, bulbous concha bullosa; OMC, osteomeatal complex

\section{Introduction}

Partial or total pneumatization of the middle turbinate is called concha bullosa. It's one of the most common anatomic variations of the lateral nasal wall. It may be presented with facial pain or headache, proper diagnosis and patient's selection is very important to achieve good results with surgery of $\mathrm{CB} .{ }^{1,2} \mathrm{CB}$ has been noted in $5-20 \%$ of the nasal specimens. However, it was found in $34 \%$ of patients having CT for the evaluation of symptomatic sinus disease. $\mathrm{CB}$ can be classified according to location of pneumatization of the concha into a lamellar concha bullosa (LCB), bulbous concha bullosa (BCB) and extensive concha bullosa.

\section{Objective}

To study the characteristics of headache due to $\mathrm{CB}$, to study the correlation between xylocaine test response and the outcome of surgery and to study the outcome of surgery (LPT) of CB in patients with headache.

\section{Patient and methods}

A prospective study designed in Al-Yarmulke Teaching Hospital, ENT department from May 2015 to March 2016. Twenty patient were included in this study ( 8 male and 12 female), their age ranged from 15 to 38 years. These twenty patients were complained from headache of rhinogenic origin. ${ }^{3}$ The endoscopic examination showing the presence of mucosal contact areas related to enlarged middle turbinate (concha bullosa on $\mathrm{CT}$ ) in contact with septum medially or in contact with lateral wall at the osteomeatal complex (OMC) region. Xylocaine test done for them. All of them were sent for CT scan of nose and par nasal sinuses. All the patients underwent surgery (lateral partial turbinectomy) under general anesthesia. Patients were followed up for 4months postoperatively. Endoscopic Surgical opening of concha bullosa (LPT) performed for all patients. Concentrating on removal or release of contact points:

a. Under GA,

b. Under endoscopic guidance with Karl story 0 degree $(4 \mathrm{~mm}$ D) \& $(180 \mathrm{~mm} \mathrm{~L})$ sinus cope and camera system.

c. After injection of anesthetic with vasoconstrictors into the concha bullosa, a sickle knife is used to make a vertical incision in the concha.

d. A pair of 5-mm endoscopic scissors' are used to continue the incision along the inferior margin of the middle turbinate to the lateral insertion of the turbinate on the lateral nasal wall. The scissors are used to continue the superior incision posterior as high but progressively moving inferiorly as the posterior region 
of turbinate, Once the lateral lamella of the turbinate has been rejected it is removed (with mucosa).

e. Middle metal packs and anterior nasal packs inserted.

\section{Results}

In our study $(60 \%)$ were female and $(40 \%)$ were male, and the third decade was the most common age group. In this study $12(60 \%)$ of our patients had complete relief of headache but 5 patients $(25 \%)$ had partial improvement and only 3 patients had no response (15\%). So in our study we have 17 (85\%) patients responded to surgery but only 3 patients with poor response (15\%). The post-operative improvement was statistically highly significant as the $\mathrm{p}$ value was 0.003 calculated by binomial method. ${ }^{4-7}$ In our study all those with complete response to xylocaine test had complete relieve of headache, and those with no improvement in their headache had partial response to xylocaine test, indicating that the xylocaine test is good prognostic indicator.

\section{Conclusion}

In patients with headache due to concha bullosa the outcome of surgery is highly significant, especially in those with good response to xylocaine test.

\section{Recommendations}

CT scan study of nose and par nasal sinuses for any patient with chronic headache with poor response to medical treatment is recommended. Xylocaine test is good diagnostic and prognostic aid, so it is recommended to be done for any patient with headache due to $\mathrm{CB}$. In view of the relapse of headaches in a few cases in some recent long-term studies, 10-20-year, long-term follow-ups are recommended to identify the exact effect of the surgery on these patients and the rate of relapse.

\section{Acknowledgments}

None.

\section{Conflicts of interest}

Author declares there are no conflicts of interest.

\section{Funding}

None.

\section{References}

1. Badran HS. Role of surgery in isolated CB. Clin Med Insights Ear Nose Throat. 2011;4:13-19.

2. Singhania Ankit. Comparison between lateral partial turbinectomy and conchoplasty for concha bullosa. National Journal of Otorhinolaryngology and Head \& Neck Surgery. 2013;1(10):2.

3. Moustafa S, Hammad, Mohammed A Gomaa. Role of some anatomical nasal abnormalities in rhinogenic headache. Egyptian Journal of Ear, Nose, Throat and Allied Sciences. 2012;13(1):31-35.

4. Nayak DR, Ramaswamy B. Endoscopic approach to middle turbinate squeeze syndrome. Indian J Otolaryngol Head Neck Surg. 2012;64(2):167-171.

5. Bektas D, Alioglu Z, Akyol N, et al. Surgical Outcomes for Rhinogenic Contact Point Headaches. Med Princ Pract. 2011;20(1):29-33.

6. Christopher Chang. Contact point headache. Fauquier ear nose \& throat consultant of Virginia. 2015.

7. Yarmohammadi ME, Ghasemi H, Pourfarzam S, et al. Effect of turbinoplasty in concha bullosa induced rhinogenic headache, a randomized clinical trial. J Res Med Sci. 2012;17(3):229-234. 